\title{
Preoperative anxiety in children aged 2-7 years old: a cross-sectional analysis of the associated risk factors
}

\author{
Yuanyuan Liang ${ }^{1 \wedge}$, Wenjiao Huang ${ }^{1}$, Xinyu Hu${ }^{1}$, Meiling Jiang ${ }^{1}$, Tian Liu ${ }^{1}$, Hong Yue ${ }^{1}$, Xiaoling Li $^{2}$ \\ ${ }^{1}$ Department of Pediatric Surgery, West China Hospital, West China School of Nursing, Sichuan University, Chengdu, China; ${ }^{2}$ West China School \\ of Nursing, Sichuan University, Chengdu, China \\ Contributions: (I) Conception and design: Y Liang, X Li; (II) Administrative support: X Li; (III) Provision of study materials or patients: Y Liang, M \\ Jiang; (IV) Collection and assembly of data: W Huang, X Hu, T Liu; (V) Data analysis and interpretation: Y Liang, H Yue; (VI) Manuscript writing: \\ All authors; (VII) Final approval of manuscript: All authors. \\ Correspondence to: Xiaoling Li. West China School of Nursing, Sichuan University, No. 37 Guoxue Xiang, Chengdu, China. Email: janifer818@163.com.
}

Background: Preoperative anxiety in children is harmful. Despite this, there is a scarcity of studies examining the incidence of preoperative anxiety and its related effects in China. This study investigated preoperative anxiety in children aged 2 to 7 in the pediatric surgery department of a tertiary hospital in China. The factors influencing preoperative anxiety in these children were identified.

Methods: The researchers used the Chinese version of the modified Yale Preoperative Anxiety Scale (CmYPAS) and the Short Form of CmYPAS (CmYPAS-SF) to assess the preoperative anxiety state of children aged 2 to 7 who underwent elective surgery in the pediatric department of a tertiary hospital in China from July 1, 2020 to September 30, 2020 were enrolled in this study. The generalized estimating equation model was used to analyze the factors influencing preoperative anxiety in children.

Results: The preoperative anxiety rate of 220 children in the tertiary hospital was $67.6 \%$. Multivariate analysis revealed that children who attended elementary school had a lower risk of preoperative anxiety compared to children who did not attend school [odd ratio $(\mathrm{OR})=0.39,95 \%$ confidence interval (CI), 0.19 to $0.79, \mathrm{P}=0.010]$. Children whose caregivers felt very worried experienced an increased risk of preoperative anxiety compared to children whose caregivers were not worried about the surgery at all (OR $=3.40,95 \%$ CI, 1.35 to $8.56, \mathrm{P}=0.009)$. Children who were very resistant, cried violently, twisted their bodies during puncturing the needle were 5.8 times more likely to experience preoperative anxiety compared to children who were very cooperative. The risk of preoperative anxiety in children who cooperated with a staff member was about 1.5 times higher than that of children who were very cooperative.

Conclusions: The incidence of preoperative anxiety in children aged 2 to 7 in the tertiary hospital in China was similar to the children in other countries. The caregivers' degree of concern priored to the operation and the degree of cooperation from the children during puncturing the indwelling needle were the main factors influencing the occurrence of preoperative anxiety.

Keywords: Preoperative anxiety in children; CmYPAS; CmYPAS-SF; anxiety status; influencing factors

Submitted Apr 20, 2021. Accepted for publication Jun 15, 2021.

doi: $10.21037 /$ tp-21-215

View this article at: https://dx.doi.org/10.21037/tp-21-215

$\wedge$ ORCID: 0000-0002-8265-1645. 


\section{Introduction}

Preoperative anxiety manifests itself as nervousness, worry, or even fear. This can result in increased blood pressure, elevated heart rate, and increased sensitivity, which can, in turn, manifest clinically as decreased pain threshold leading to increased postoperative pain, greater demand for analgesics, and increased agitation and delirium during recovery, all of which can seriously affect the outcome of the operation and rehabilitation of the patient (1). For children, preoperative anxiety can be more harmful than in adults. First, children are more likely to experience increased autonomic nervous activity compared to adults, leading to prolonged anesthesia induction time, anesthesia duration, and recovery time $(2,3)$. Second, fear of the unknown hinders a child's ability to adapt to unfamiliar medical environments and may increase the incidence of accidental injuries. Furthermore, children with anxiety before surgery are 3 times more likely to experience delirium, nightmares, separation anxiety, sleep disorders, crying at night, enuresis, tantrums, apathy, withdrawal, eating disorders, attacks on authority, and negative behavioral changes such as increased fear of medical staff (4-9). Studies have shown that these negative behaviors can be observed even one year after discharge from the hospital (10) and may even have a long-term negative impact on the child's future medical interactions and hinder their normal growth and development (4). Researches from other countries have reported that about $65-80 \%$ of children will experience preoperative anxiety $(11,12)$. This is complicated further by the psychological characteristics of 2 to 7 years old preschool children who are generally more variable, impulsive, and react unintentionally. They are aware of the existence of their parents and are more likely to experience fear and separation anxiety (13-15). After the age of 8 years, children tend to be more accepting, and with persuasion, these children can start to tolerate separation. Therefore, preoperative anxiety in children, especially pre-school children, is a clinical problem that demands more attention.

There are extensive studies in other countries on children's anxiety during the perioperative period. However, there are numerous differences between China and other countries with regards to the growth environment, educational concepts, and children's relationship with their parents. Therefore, the research experience of other countries may not be relevant to China. The belated research into children's preoperative anxiety in China has mainly focused on interventions without a clear understanding of the current status of preoperative anxiety in Chinese children, and hence the intervention protocols lack pertinence.

This study investigated the preoperative anxiety status in children aged 2 to 7 years in a tertiary hospital in China. The factors influencing preoperative anxiety in these children were identified. This information will form the basis for the development of targeted preoperative anxiety intervention measures for young children. We present the following article in accordance with the STROBE reporting checklist (available at https://dx.doi.org/10.21037/tp-21-215).

\section{Methods}

\section{Participants}

Children aged 2 to 7 years old who underwent elective surgery in the pediatric surgery department of a tertiary hospital in China from July 1, 2020 to September 30, 2020 were selected for this study.

Children were included if they satisfied the following inclusion criteria: (I) children aged 2 to 7 years undergoing elective surgery; (II) the children's guardians or caregivers voluntarily participated in this project and provided informed consent; (III) the children's caregiver has an acceptable ability to read, write, and speak Chinese.

The following exclusion criteria were applied: (I) children with confirmed developmental delay or mood anxiety disorder; (II) children who were administered preoperative sedative drugs; (III) children living in a non-Chinese language and cultural background; and (IV) children who were asleep during the preoperative monitoring period.

\section{Sample size}

This cross-sectional survey study was designed to investigate the incidence of preoperative anxiety in children in a tertiary hospital in China. The overall rate was estimated to be $60 \%$, thus a two-sided test was used, with significance set at 0.05 and allowable error set at 0.1 . The sample size was $\mathrm{N}=100$, calculated using PASS 15 software. Assuming 20\% loss to follow-up/disqualification, at least 125 cases must be included in this study as the research target.

\section{Research tools}

Questionnaire regarding the basic characteristics of the children

The in-house-designed questionnaire included basic 
characteristics of the patients such as age, gender, ethnicity, type of operation, education status, history of hospitalization or operation, family type, ability to pay for this hospitalization, hospital care, the degree of caregiver anxiety related to the child's surgery, and the degree of cooperation during placement of the indwelling needle. The type of surgery is defined according to the surgical level, with first and second level operations regarded as minor operations, and third and fourth level operations regarded as major operations.

The Chinese version of the modified Yale Preoperative Anxiety Scale (CmYPAS)

The CmYPAS is an observational behavioral scale specifically designed to evaluate preoperative anxiety in children aged 2-12 years. The mYPAS compiled by Kain (16) was adapted and translated into Chinese by Guan and colleagues (17) with good reliability and validity. Using this scale, the child's anxiety state can be assessed within 1 minute. The scale contains the following five dimensions: activity, occurrence, emotional expression, obvious alertness, and dependence on parents. Each dimension has four behavioral descriptions, with the exception of the second dimension which has six behavioral descriptions. The scoring method is: the scores of the four behavior descriptions selected in the first, third, fourth, and five dimensions are 0.25, 0.5, 0.75, and 1.0, respectively, and the scores of the six behavior descriptions selected in the second dimension are respectively 0.1667 , $0.333,0.500,0.667,0.833,1.0$. The total scores of the 5 dimensions are added and multiplied by 20 and converted into a percentile system. The CmYPAS score ranges from 23.333 to 100 points. The degree of anxiety is divided into groups for each 30 points (18). The higher the score, the greater the degree of preoperative anxiety experienced by the child.

\section{The simplified Chinese version of the modified Yale Preoperative Anxiety Scale-Short Form (CmYPAS-SF)} Considering that children are not always accompanied by their parents before surgery, in order to accurately assess the anxiety state of children before surgery, this study also used the CmYPAS-SF. The Chinese version of the scale was translated by Dai et al. (19). This simplified scale has good reliability and validity. Compared with mYPAS, the dimension of dependence on parents is subtracted. The remaining dimensions and the scoring methods are the same as for mYPAS. The final score is multiplied by 25 and converted into a percentile system. The total possible score ranges from 22.917 to 100 points.

\section{Research methods}

On the morning of the operation, the researcher introduced the content, purpose, significance, and process of the study to the children and their caregivers in detail. After obtaining signed informed consent from the children and their caregivers, the basic data of the children was collated. The researchers used CmYPAS to assess the anxiety of the children at two time points, namely just as they exited the operating room elevator (T1) and inside the preoperative waiting room (T2). The CmYPAS-SF was used at the next two time points, namely when children entered the operating room (T3) and during the anesthesia induction period (T4). The anxiety state at each time point was assessed.

\section{Statistical analysis}

The SPSS 24.0 software was used for data processing and statistical analyses. Measurement data are expressed as mean \pm standard deviation, and count data are expressed as rate. According to data type, the $t$-test, rank sum test, chi-square test, adjusted chi-square test, or Fisher's exact test was used. Univariate analysis was conducted to assess the correlation of different factors with preoperative anxiety, and the generalized estimating equation model was used to analyze the factors influencing preoperative anxiety in children. A two-sided test was used, and the significance level was set at $\alpha=0.05$.

\section{Ethical principles}

All procedures performed in this study involving human participants were in accordance with the Declaration of Helsinki (as revised in 2013). This study has been reviewed and approved by the Institute's Biomedical Ethics Committee in the hospital (approval number: \#2019849).

\section{Results}

\section{Inclusion of research subjects}

A total of 220 patients who underwent elective surgery between July 1, 2020 and September 30, 2020 were enrolled in this study. The average age of the children was $4.54 \pm 1.71$ years. The basic characteristics of the research subjects are shown in Table 1. 
Table 1 Basic characteristics of the enrolled patients ( $\mathrm{N}=220)$

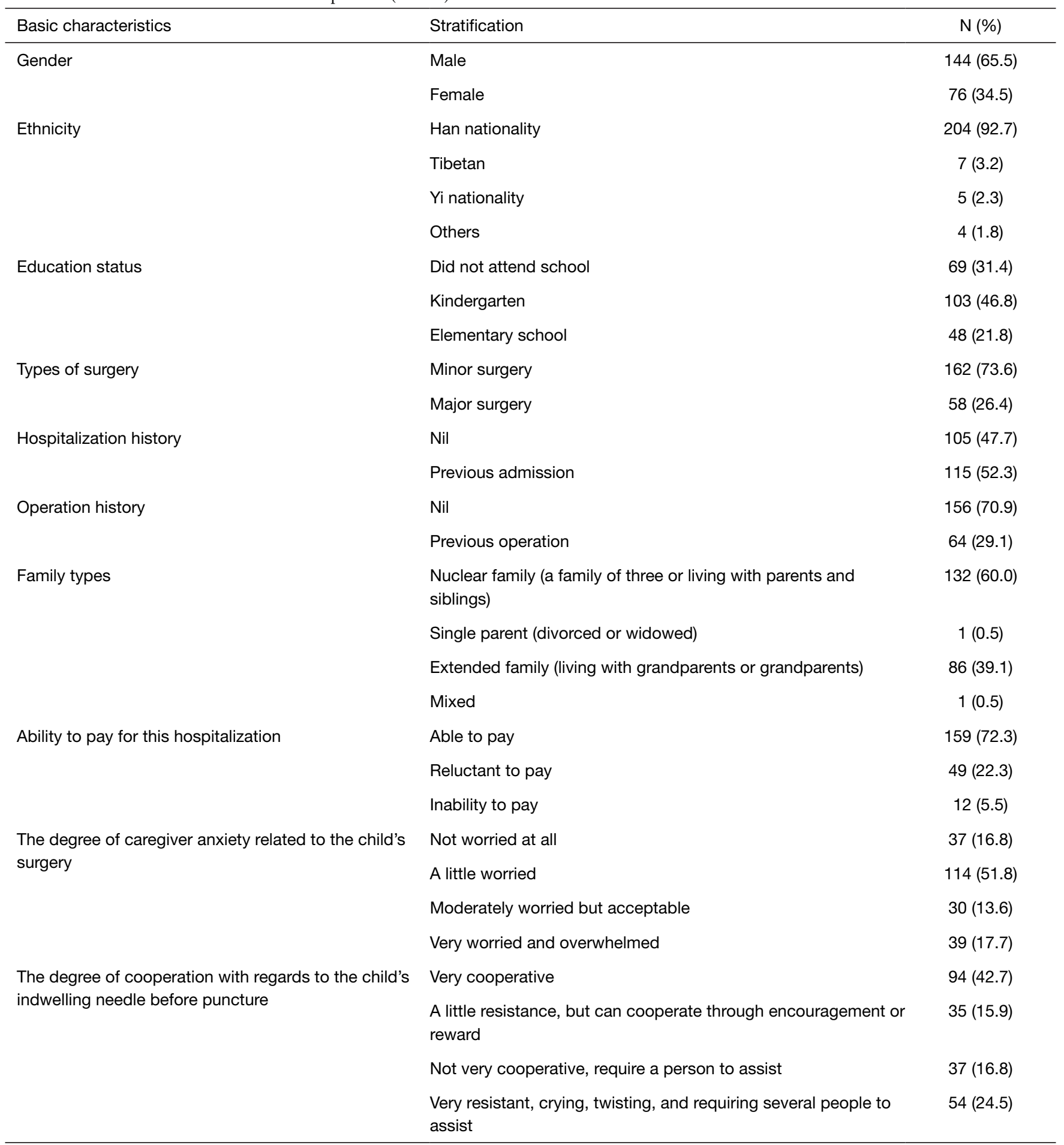




\section{The status and univariate analysis of preoperative anxiety in children aged 2 to 7 years}

The incidence of anxiety at the 4 preoperative times for the 220 children was $67.6 \%$. Univariate analysis (Table 2) showed that children's preoperative anxiety was significantly different at each of the preoperative assessment time points. Different characteristics such as educational status, also significantly affected preoperative anxiety. There were significant correlations between risk of preoperative anxiety and each of the following: history of hospitalization and surgery, degree of the caregiver's anxiety regarding the child's surgery, and the degree of cooperation during placement of the indwelling needle (Table 2). As the sample size of Tibetan, $\mathrm{Yi}$, and other ethnic groups was small, the three groups were combined and designated "others" for univariate analysis. Similarly, since "reluctant to pay" and "inability to pay" both suggest economic strain, these were combined and designated the "barely/unpayable" group.

\section{Multivariate analysis of preoperative anxiety in children aged 2 to 7 years}

Multivariate analyses (Table 3) demonstrated a statistically significant difference in the incidence of anxiety among children at the four different time points prior to surgery. The risk of preoperative anxiety was significantly decreased in children who attend elementary school compared to children who do not attend school [odds ratio $(\mathrm{OR})=0.39$, $95 \%$ confidence interval $(\mathrm{CI}), 0.19$ to $0.79, \mathrm{P}=0.010$ ]. The risk of preoperative anxiety was significantly higher in children whose caregivers felt very worried and overwhelmed compared to children whose caregivers were not worried at all about the operation $(\mathrm{OR}=3.40,95 \%$ CI, 1.35 to $8.56, \mathrm{P}=0.009)$. The degree of cooperation in indwelling the needle before puncture will affect the risk of preoperative anxiety in children.

\section{Discussion}

The current status of preoperative anxiety in children aged 2 to 7 years

In this study, the incidence of preoperative anxiety in children aged 2 to 7 years in China was $67.6 \%$, which was comparable to that observed in other countries (11). The incidences of anxiety at the 4 assessment time points were $50.5 \%, 62.3 \%, 78.6 \%$, and $79.1 \%$. Using $\mathrm{T} 1$ as the references, that is, the time point at which the children exited the operating room elevator, the incidence of anxiety increased by $84.0 \%$ by the time they reached the preoperative waiting area (T2). When the children reached the operating room (T3), anxiety had increased by approximately 3.812 times compared to T1, and during the induction of anesthesia (T4) anxiety was elevated by about 3.965 fold compared to T1. The main reason for this dramatic increase in anxiety in the operating room can be explained by the implementation of hospital epidemic protocols which only allowed caregivers to accompany patients in the preoperative waiting area. Caregivers were not permitted to enter the operating room and this separation significantly changed the child's preoperative anxiety levels. It was also noted that some parents provided psychological comfort while caring for their children. When these children were separated from their carers, they may be nervous, expressionless, and even ask questions repeatedly. In a few patients, anxiety manifested as weeping, crying, or even fleeing. One child in this study experienced chronic pain and as part of the psychological comfort, his mother repeatedly emphasized that the surgery will prevent the recurrence of pain. As a result, this child showed a positive response to the surgery, with little preoperative anxiety.

Preoperative anxiety can cause great and far-reaching harm to children. In this study, 48 of the 220 preoperative children attended primary school, and the risk of anxiety in this group was significantly reduced by $61.2 \%$ compared to children who did not attend school. Kindergarten children also showed a reduced risk of anxiety compared to children who did not attend school, however, the difference was not statistically significant. Children who are not enrolled in school tend to have insufficient cognitive understanding about diseases or surgery, inaccurate descriptions of their own emotions, and their emotional expressions are often different from older children. This study demonstrated that children who are not enrolled in school are more likely to have preoperative anxiety, and this is consistent with the results of Kain et al. and Mccann et al. (13-15).

\section{The influence of caregiver anxiety on children's preoperative anxiety}

To date, the effects of parental presence on child anxiety has remained controversial. Kain and colleagues suggested that parental presence does not affect the incidence of anxiety in children (20-22). However, many other studies have suggested that parental presence can reduce a child's anxiety and enhance cooperation, which is beneficial for 
Table 2 Univariate analysis of preoperative anxiety in children aged 2 to 7 years

\begin{tabular}{|c|c|c|c|c|c|}
\hline Variables & Total (N) & Without anxiety, N (\%) & With anxiety, N (\%) & Statistical value & Point probability \\
\hline $\mathrm{T} 1$ & $220(25.0)$ & $109(49.5)$ & $111(50.5)$ & & \\
\hline $\mathrm{T} 2$ & $220(25.0)$ & $83(37.7)$ & $137(62.3)$ & & \\
\hline T3 & $220(25.0)$ & $47(21.4)$ & $173(78.6)$ & & \\
\hline Gender & & & & $2.051^{\mathrm{a}}$ & 0.152 \\
\hline Male & $576(65.5)$ & $196(68.8)$ & 380 (63.9) & & \\
\hline Female & $304(34.5)$ & $89(31.2)$ & $215(36.1)$ & & \\
\hline Ethnicity & & & & $1.720^{\mathrm{a}}$ & 0.190 \\
\hline Education status & & & & $56.359^{a}$ & $<0.001$ \\
\hline Did not attend school & $276(31.4)$ & $47(16.5)$ & 229 (38.5) & & \\
\hline Kindergarten & $412(46.8)$ & $143(50.2)$ & 269 (45.2) & & \\
\hline Elementary school & $192(21.8)$ & 95 (33.3) & $97(16.3)$ & & \\
\hline Types of surgery & & & & $0.000^{\mathrm{a}}$ & 0.982 \\
\hline Minor surgery & 648 (73.6) & $210(73.7)$ & 438 (73.6) & & \\
\hline Major surgery & $232(26.4)$ & $75(26.3)$ & $157(26.4)$ & & \\
\hline Hospitalization history & & & & $12.004^{\mathrm{a}}$ & 0.001 \\
\hline Family types & & & & $2.359^{b}$ & 0.494 \\
\hline $\begin{array}{l}\text { Nuclear family (a family of three or living } \\
\text { with parents, siblings) }\end{array}$ & $528(60.0)$ & $178(62.5)$ & $350(58.8)$ & & \\
\hline Single parent (divorced or widowed) & $4(0.5)$ & $1(0.4)$ & $3(0.5)$ & & \\
\hline $\begin{array}{l}\text { Extended family (living with grandparents } \\
\text { or grandparents) }\end{array}$ & $344(39.1)$ & $106(37.2)$ & $238(40.0)$ & & \\
\hline Recombinant & $4(0.5)$ & $0(0.0)$ & $4(0.7)$ & & \\
\hline Ability to pay for this hospitalization & & & & $2.601^{b}$ & 0.107 \\
\hline Ability to pay & $636(72.3)$ & $216(75.8)$ & $420(70.6)$ & & \\
\hline Reluctant/unpayable payment & $244(27.7)$ & $69(24.2)$ & $175(29.4)$ & & \\
\hline
\end{tabular}

Table 2 (continued) 
Table 2 (continued)

\begin{tabular}{|c|c|c|c|c|c|}
\hline Variables & Total (N) & Without anxiety, N (\%) & With anxiety, N (\%) & Statistical value & Point probability \\
\hline Not worried at all & $148(16.8)$ & 55 (19.3) & $93(15.6)$ & & \\
\hline A little worried & $456(51.8)$ & $157(55.1)$ & 299 (50.3) & & \\
\hline $\begin{array}{l}\text { The degree of cooperation in the child's } \\
\text { indwelling needle before puncture }\end{array}$ & & & & $82.988^{a}$ & $<0.001$ \\
\hline Very cooperative & $376(42.7)$ & $176(61.8)$ & $200(33.6)$ & & \\
\hline $\begin{array}{l}\text { Very resistant, crying, twisting, and } \\
\text { needing several people to press }\end{array}$ & $216(24.5)$ & $26(9.1)$ & $190(31.9)$ & & \\
\hline
\end{tabular}

Note: ${ }^{a}$, Chi-square test $\chi^{2}$ value; ${ }^{b}$, Fisher exact probability.

both parents and anesthesiologists (23-25). The results of this current study demonstrated that children experienced significantly higher anxiety in the absence of their caregiver, that is, at the moment of entering the operating room (T3) and during the anesthesia induction period (T4), compared to when they were with their caregiver, namely, when they were in the elevator (T1) and in the preoperative waiting area (T2). Interestingly, however, the presence of an anxious caregiver led to an increase in preoperative anxiety in children. The specific manifestation is that when the caregiver is very worried and overwhelmed, the risk of anxiety in children may be increased. Indeed, children with anxious caregivers were 2.4 times more likely to experience preoperative anxiety. Therefore, while it may be beneficial to have a caregiver with the patient during the administration of anesthesia, consideration should be given to the personality and anxiety characteristics of the caregivers. Caregivers who are prone to morbid anxiety or whose personality is more anxious are not suitable for escorting children during the induction of anesthesia.

\section{The influence of preoperative puncture experience on children's preoperative anxiety}

There is still much controversy regarding whether anesthesia in children should be induced via intravenous injection or mask inhalation. Some believe that conscious venipuncture and parental separation can cause too much anxiety $(13,26)$, and thus the inhalation method should be used to induce anesthesia to reduce trauma to the child. In the United States, inhalation induction is also the most common anesthesia induction technique. However, in many other countries in the world, intravenous induction is more common, as experience has shown that children are not only afraid of needles, but they are also apprehensive about face masks. Under normal circumstances, it is difficult for children to accept any foreign objects on their face and most children will immediately show resistance. Furthermore, as the concentration of volatile anesthetics increases, an unfamiliar, pungent smell is usually produced in the mask, and even the most well-prepared older children will become agitated $(27,28)$. Consistent with the findings of Aguilera et al. (29), our current study demonstrated that the unpleasant preoperative puncture experience increased the risk of preoperative anxiety in children. Specifically, when the needle was placed before the puncture, the children became very resistant, cried, twisted, and required several people to assist. The risk of preoperative anxiety was about 5.8 times higher than that of a very cooperative child. The risk of preoperative anxiety in children who 
Table 3 Multivariate analysis of preoperative anxiety in children aged 2 to 7 years

\begin{tabular}{|c|c|c|c|c|c|c|c|c|}
\hline Variables & Groups & $\mathrm{B}$ & Std. Error & $\begin{array}{c}\text { Wald } \\
\text { Chi-Square }\end{array}$ & Sig. & OR & \multicolumn{2}{|c|}{$\begin{array}{c}95 \% \text { Wald } \\
\text { confidence interval } \\
\text { for OR }\end{array}$} \\
\hline \multirow[t]{3}{*}{ Assessment times } & $\mathrm{T} 4$ & 1.602 & 0.2092 & 58.660 & 0.000 & 4.965 & 3.295 & 7.482 \\
\hline & T3 & 1.571 & 0.2038 & 59.413 & 0.000 & 4.812 & 3.227 & 7.174 \\
\hline & $\mathrm{T} 1^{*}$ & 0 & & & & 1 & & \\
\hline \multirow[t]{3}{*}{ Education status } & Elementary school & -0.947 & 0.3655 & 6.715 & 0.010 & 0.388 & 0.189 & 0.794 \\
\hline & Kindergarten & -0.592 & 0.3219 & 3.378 & 0.066 & 0.553 & 0.294 & 1.040 \\
\hline & Did not attend school ${ }^{*}$ & 0 & & & & 1 & & \\
\hline \multirow[t]{2}{*}{ Operation history } & Previous operation & -0.090 & 0.3070 & 0.085 & 0.770 & 0.914 & 0.501 & 1.669 \\
\hline & Never ${ }^{\star}$ & 0 & & & & 1 & & \\
\hline \multirow{4}{*}{$\begin{array}{l}\text { The degree of anxiety of } \\
\text { the caregivers about the } \\
\text { child's surgery }\end{array}$} & Very worried and overwhelmed & 1.225 & 0.4705 & 6.778 & 0.009 & 3.404 & 1.354 & 8.560 \\
\hline & $\begin{array}{l}\text { Moderately worried but } \\
\text { acceptable }\end{array}$ & -0.400 & 0.4157 & 0.924 & 0.336 & 0.671 & 0.297 & 1.515 \\
\hline & A little worried & -0.023 & 0.2976 & 0.006 & 0.939 & 0.978 & 0.546 & 1.752 \\
\hline & Not worried at all ${ }^{*}$ & 0 & & & & 1 & & \\
\hline \multirow{2}{*}{$\begin{array}{l}\text { The degree of } \\
\text { cooperation regarding } \\
\text { the child's indwelling } \\
\text { needle before puncture }\end{array}$} & $\begin{array}{l}\text { Very resistant, crying, twisting, } \\
\text { and needing several people to } \\
\text { assist }\end{array}$ & 1.766 & 0.4268 & 17.118 & 0.000 & 5.845 & 2.533 & 13.492 \\
\hline & Very cooperative* & 0 & & & & 1 & & \\
\hline
\end{tabular}

Note: *Reference group.

required assistance by personnel was about 1.5 times higher than that of very cooperative children. There was no risk of preoperative anxiety in children who showed little resistance and could cooperate through encouragement or rewards. Similarly, very cooperative children had no risk of preoperative anxiety. Therefore, when conscious venipuncture before surgery is inevitable, medical staff and caregivers should encourage children to face the needle bravely through encouraging words and patient explanations, or local topical anesthetics can be applied to reduce pain during needle puncture to minimize fear (30).

Identifying the influencing factors of preoperative anxiety in children plays a crucial role in reducing preoperative anxiety. Because the stacking of interventions is not the better and generalized interventional methods have not always been successful. Kain et al. (31) found that a well-designed and costly preoperative behavioral plan had a limited effect on minimizing anxiety and had no significant beneficial effect on the induction of anesthesia. Therefore, management of preoperative anxiety should be based on 
the conditions of the particular hospital, the characteristics of the medical group, individual differences, and repeated clinical experience.

There are many influencing factors for the occurrence of preoperative anxiety in children. Among them, some influencing factors are objective facts which cannot be changed, and some influencing factors are caused by long-term living environment influences which cannot be effective through short-term intervention during hospitalization. So it is very necessary to investigate the possible influencing factors that can cause or affect preoperative anxiety in children and can be intervened in a short time during hospitalization. This study showed that the degree of concern experienced by the caregivers regarding the child's surgery and the degree of cooperation from the child before placement of the indwelling needle were the main influencing factors for the child's preoperative anxiety. Targeted intervention measures should be conducted to reduce the child's incidence of preoperative anxiety and reduce the associated harm.

\section{Study limitations and suggestions for follow-up research}

There were several limitations to this study. First, in addition to the influencing factors shown in the survey conclusions, this study conducted interviews with some children's caregivers during the investigation and determined that the children's preoperative anxiety may be related to the caregivers. Indeed, the caregiver's cognition and the child's personality traits may be related. In cases where the caregiver expressed that the child would be unable to cooperate with the medical treatment and would cry violently, the child was often assessed as having preoperative anxiety. However, this study may be limited by the lack of investigation into the personality characteristics of all the subjects included and the cognition of the caregivers. Second, this study was limited by manpower, time, and region, and only a single-center status survey was conducted. Thus, the relationship between risk factors and preoperative stress was merely exploratory. Future follow-up studies involving multi-centers in different regions should be conducted to confirm the causal relationship between risk factors and preoperative anxiety in children.

\section{Conclusions}

The incidence of preoperative anxiety in children aged 2 to 7 years in our tertiary hospital in China was similar to the incidence of preoperative anxiety in children in other countries. The degree of concern of the caregivers prior to the operation and the degree of cooperation from the child during placement of the indwelling needle were the main factors influencing the occurrence of preoperative anxiety. Interventions should be designed to reduce the incidence of preoperative anxiety in children.

\section{Acknowledgments}

Funding: None.

\section{Footnote}

Reporting Checklist: The authors have completed the STROBE reporting checklist. Available at https://dx.doi. org/10.21037/tp-21-215

Data Sharing Statement: Available at https://dx.doi. org/10.21037/tp-21-215

Conflicts of Interest: All authors have completed the ICMJE uniform disclosure form (available at https://dx.doi. org/10.21037/tp-21-215). The authors have no conflicts of interest to declare.

Ethical Statement: The authors are accountable for all aspects of the work in ensuring that questions related to the accuracy or integrity of any part of the work are appropriately investigated and resolved. All procedures performed in this study involving human participants were in accordance with the Declaration of Helsinki (as revised in 2013) and the study was approved by the Ethics Committee of the West China Hospital, Sichuan University (\#2019849). The children's guardians or caregivers voluntarily participated in this project and provided informed consent.

Open Access Statement: This is an Open Access article distributed in accordance with the Creative Commons Attribution-NonCommercial-NoDerivs 4.0 International License (CC BY-NC-ND 4.0), which permits the noncommercial replication and distribution of the article with the strict proviso that no changes or edits are made and the original work is properly cited (including links to both the formal publication through the relevant DOI and the license). See: https://creativecommons.org/licenses/by-nc-nd/4.0/. 


\section{References}

1. Britteon P, Cullum N, Sutton M. Association between psychological health and wound complications after surgery. Br J Surg 2017;104:769-76.

2. Aytekin A, Doru Ö, Kucukoglu S. The Effects of Distraction on Preoperative Anxiety Level in Children. J Perianesth Nurs 2016;31:56-62.

3. Cumino DO, Vieira JE, Lima LC, et al. Smartphonebased behavioural intervention alleviates children's anxiety during anaesthesia induction: A randomised controlled trial. Eur J Anaesthesiol 2017;34:169-75.

4. Ahmed MI, Farrell MA, Parrish K, et al. Preoperative anxiety in children risk factors and non-pharmacological management. Middle East J Anaesthesiol 2011;21:153-64.

5. Drasković B, Simin JM, Kvrgić IM. Psychological aspects of pediatric anesthesia. Med Pregl 2015;68:29-34.

6. Gooden R, Tennant I, James B, et al. The incidence of emergence delirium and risk factors following sevoflurane use in pediatric patients for day case surgery, Kingston, Jamaica. Rev Bras Anestesiol 2014;64:413-8.

7. Aldakhil SK, Salam M, Albelali AA, et al. The prevalence of emergence delirium and its associated factors among children at a postoperative unit: A retrospective cohort at a Middle Eastern hospital. Saudi J Anaesth 2020;14:169-76.

8. Aykut A, I 1k B. Emotion regulation and premedication success relationship in children who underwent general anesthesia Turk J Med Sci 2018;48:217-22.

9. Barreto ACTP, Rangel da Rocha Paschoal AC, Barbosa Farias C, et al. Risk factors associated with anesthesia emergence delirium in children undergoing outpatient surgery. Braz J Anesthesiol 2018;68:162-7.

10. Kain ZN, Mayes LC, Caldwell-Andrews AA, et al. Preoperative anxiety, postoperative pain, and behavioral recovery in young children undergoing surgery. Pediatrics 2006;118:651-8.

11. Dreger VA, Tremback TF. Management of preoperative anxiety in children. AORN J 2006;84:778-80, 782-6, 78890 passim; quiz 805-8.

12. Fortier MA, Martin SR, Chorney JM, et al. Preoperative anxiety in adolescents undergoing surgery: a pilot study. Paediatr Anaesth 2011;21:969-73.

13. Kain ZN, Mayes LC, O'Connor TZ, et al. Preoperative anxiety in children. Predictors and outcomes. Arch Pediatr Adolesc Med 1996;150:1238-45.

14. McCann ME, Kain ZN. The management of preoperative anxiety in children: an update. Anesth Analg 2001;93:98-105.
15. Zhou GX. Nursing intervention of separation anxiety in children before operation. Journal of Nursing 2012;27:80-1.

16. Kain ZN, Mayes LC, Cicchetti DV, et al. The Yale Preoperative Anxiety Scale: how does it compare with a "gold standard"? Anesth Analg 1997;85:783-8.

17. Mo WP, Chen L, Guan H, et al. Research progress on the modified Yale preoperative anxiety scale at home and abroad. Journal of Nursing 2018;25:17-20.

18. Cumino Dde O, Cagno G, Gonçalves VF, et al. Impact of preanesthetic information on anxiety of parents and children. Braz J Anesthesiol 2013;63:473-82.

19. Dai Y, Zheng XL, Shu LL, et al. The Chinese version and reliability and validity of the simplified modified Yale Preoperative Anxiety Scale. Nursing Research 2019;33:2596-9.

20. Kain ZN, Mayes LC, Wang SM, et al. Parental presence during induction of anesthesia versus sedative premedication: which intervention is more effective? Anesthesiology 1998;89:1147-56; discussion 9A-10A.

21. Kain ZN, Caldwell-Andrews AA, Maranets I, et al. Predicting which child-parent pair will benefit from parental presence during induction of anesthesia: a decision-making approach. Anesth Analg 2006;102:81-4.

22. Akinci SB, Köse EA, Ocal T, et al. The effects of maternal presence during anesthesia induction on the mother's anxiety and changes in children's behavior. Turk J Pediatr 2008;50:566-71.

23. Watson AT, Visram A. Children's preoperative anxiety and postoperative behaviour. Paediatr Anaesth 2003;13:188-204.

24. Kain ZN, Mayes LC, Wang SM, et al. Parental presence and a sedative premedicant for children undergoing surgery: a hierarchical study. Anesthesiology 2000;92:939-46.

25. Messeri A, Caprilli S, Busoni P. Anaesthesia induction in children: a psychological evaluation of the efficiency of parents' presence. Paediatr Anaesth 2004;14:551-6.

26. Kain ZN, Wang SM, Mayes LC, et al. Sensory stimuli and anxiety in children undergoing surgery: a randomized, controlled trial. Anesth Analg 2001;92:897-903.

27. Hamilton JG. Needle phobia: a neglected diagnosis. J Fam Pract 1995;41:169-75.

28. Przybylo HJ, Tarbell SE, Stevenson GW. Mask fear in children presenting for anesthesia: aversion, phobia, or both? Paediatr Anaesth 2005;15:366-70.

29. Aguilera IM, Patel D, Meakin GH, et al. Perioperative anxiety and postoperative behavioural disturbances in 
children undergoing intravenous or inhalation induction of anaesthesia. Paediatr Anaesth 2003;13:501-7.

30. Zielinska M, Holtby H, Wolf A. Pro-con debate: intravenous vs inhalation induction of anesthesia in

Cite this article as: Liang $\mathrm{Y}$, Huang W, Hu X, Jiang M, Liu T, Yue H, Li X. Preoperative anxiety in children aged 2-7 years old: a cross-sectional analysis of the associated risk factors. Transl Pediatr 2021;10(8):2024-2034. doi: 10.21037/tp-21-215 children. Paediatr Anaesth 2011;21:159-68.

31. Kain ZN, Caramico LA, Mayes LC, et al. Preoperative preparation programs in children: a comparative examination. Anesth Analg 1998;87:1249-55. 